\title{
Contrasting gene flow at different spatial scales revealed by genotyping-by-sequencing in Isocladus armatus, a massively colour polymorphic New Zealand marine isopod
}

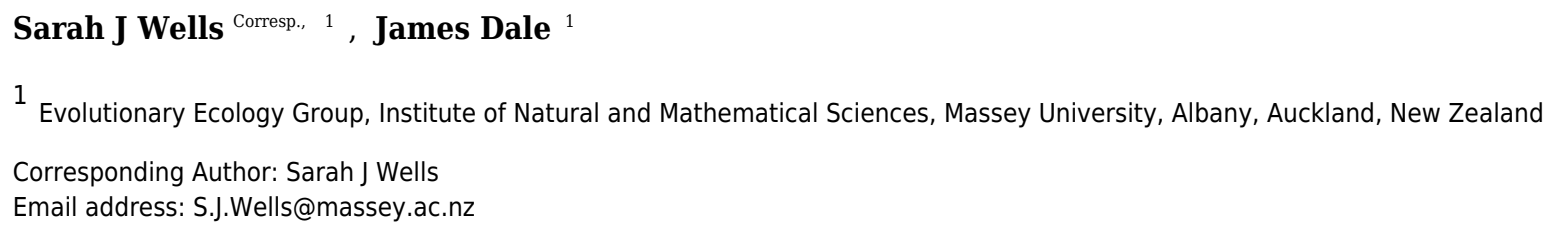

Understanding how genetic diversity is maintained within populations is central to evolutionary biology. Colour polymorphism (CP) research, which typically has a genetic basis, can shed light on this issue. However, because gene flow can homogenise genetic variation, understanding population connectivity is critical in examining the maintenance of polymorphisms. In this study we assess the utility of genotyping-by-sequencing to resolve gene flow, and provide a preliminary investigation into the genetic basis of CP in Isocladus armatus, an endemic New Zealand marine isopod. Analysis of the genetic variation in 4,000 single nucleotide polymorphisms (SNPs) within and among populations and colour morphs revealed large differences in gene flow across two spatial scales. Marine isopods, which lack a pelagic larval phase, are typically assumed to exhibit greater population structuring than marine invertebrates possessing a biphasic life cycle. However, we found high gene flow rates and no genetic subdivision between two North Island populations situated $8 \mathrm{~km}$ apart. This suggests that $I$. armatus is capable of substantial dispersal along coastlines. In contrast, we identified a strong genetic disjunction between North and South Island populations. This result is similar to those reported in other New Zealand marine species, and is congruent with the presence of a geophysical barrier to dispersal down the east coast of New Zealand. We also found some support for a genetic basis to colouration evidenced by positive $\mathrm{F}_{\mathrm{ST}}$ outlier tests, with two SNPs in particular showing strong association to the expression of a striped morph. Our study provides one of the first population genomic studies of a marine organism in New Zealand, and suggests that genotyping-by-sequencing can be a good alternative to more traditional investigations based on traditional markers such as microsatellites. Our study provides a foundation for further development of a highly tractable system for research on the evolutionary maintenance of $\mathrm{CP}$. 


\title{
1 Contrasting gene flow at different spatial scales revealed by
}

\section{2 genotyping-by-sequencing in Isocladus armatus, a massively}

\section{3 colour polymorphic New Zealand marine isopod}

\author{
4 Sarah J. Wells ${ }^{1}$, James Dale ${ }^{1}$ \\ $5{ }^{1}$ Evolutionary Ecology Group, Institute of Natural and Mathematical Sciences, Massey \\ 6 University, Albany, Auckland, New Zealand \\ 7 \\ 8 Corresponding Author: \\ 9 Sarah Wells ${ }^{1}$ \\ 10 Private Bag 102904, North Shore Mail Centre, Albany, Auckland, New Zealand \\ 11 Email address: $\underline{\text { S.J.Wells@massey.ac.nz }}$
}


12

13

14

\section{ABSTRACT}

Understanding how genetic diversity is maintained within populations is central to evolutionary biology. Colour polymorphism (CP) research, which typically has a genetic basis, can shed light on this issue. However, because gene flow can homogenise genetic variation, understanding population connectivity is critical in examining the maintenance of polymorphisms. In this study we assess the utility of genotyping-by-sequencing to resolve gene flow, and provide a preliminary investigation into the genetic basis of CP in Isocladus armatus, an endemic New Zealand marine isopod. Analysis of the genetic variation in 4,000 single nucleotide polymorphisms (SNPs) within and among populations and colour morphs revealed large differences in gene flow across two spatial scales. Marine isopods, which lack a pelagic larval phase, are typically assumed to exhibit greater population structuring than marine invertebrates possessing a biphasic life cycle. However, we found high gene flow rates and no genetic subdivision between two North Island populations situated $8 \mathrm{~km}$ apart. This suggests that $I$. armatus is capable of substantial dispersal along coastlines. In contrast, we identified a strong genetic disjunction between North and South Island populations. This result is similar to those reported in other New Zealand marine species, and is congruent with the presence of a geophysical barrier to dispersal down the east coast of New Zealand. We also found some support for a genetic basis to colouration evidenced by positive $\mathrm{F}_{\mathrm{ST}}$ outlier tests, with two SNPs in particular showing strong association to the expression of a striped morph. Our study provides one of the first population genomic studies of a marine organism in New Zealand, and suggests that genotyping-by-sequencing can be a good alternative to more traditional investigations based on traditional markers such as microsatellites. Our study provides a foundation for further development of a highly tractable system for research on the evolutionary maintenance of CP. 
36 A key challenge in evolutionary biology is to understand the mechanisms maintaining genetic

37 diversity in natural populations (Barton \& Turelli 1989; Brooks 2002; Endler 1986; Futuyma 2005; Hartl \& Clark 1997; Hedrick 1986; Hedrick 2006; Kotiaho, Simmons \& Tomkins 2001; Lewontin 1974; Nei 1975; Pamilo 1988; Roulin 2004). Maintenance of diversity is paradoxical because both directional selection and genetic drift should act to remove most variation from populations (Ford 1964; Futuyma 2005; Hartl \& Clark 1997). However, diversity can be maintained in the presence of the homogenizing effect of gene flow among populations (Kawecki \& Ebert 2004). Therefore, resolving population structure in high gene flow species is critical to understanding how genetic variation is maintained within populations in the face of local adaptation. Research on colour polymorphism (CP), including how gene flow affects $\mathrm{CP}$ within and among populations, provides an excellent opportunity to gain insight into the evolutionary mechanisms that maintain biological diversity because $\mathrm{CP}$ is quantifiable and can occur on an immense scale (Roulin 2004).

49 The spatial scales over which organisms and genes interact in the terrestrial and marine environments are often highly divergent. For example, the lack of physical barriers to gene flow, combined with the biphasic life cycles of many marine organisms, mean that the scales over which genetic structure may occur in the oceans can be considerably larger than in the terrestrial environment (Palumbi, 2004; Cowen and Sponaugle, 2009). These premises present challenges

54 for effectively assessing gene flow in the marine environment, and are compounded by the large spatial scale, heterogeneous dynamic processes, and asymmetric flows of seascapes (Riginos et al., 2016). 
57 Nevertheless, population genetic differentiation is generally expected to be greater in species

58 with direct development than in organisms exhibiting biphasic life cycles, because of the reduced

59 dispersal abilities of juveniles in these species (Benzie 2000; Ross et al. 2009; but see Weersing

$60 \&$ Toonen 2009). The lack of a pelagic larval stage in the Isopoda, accompanied by the brooding

61 of young and internal fertilisation, are purported to be limiting factors in their dispersal.

62 Accordingly, population genetic studies in the Isopoda have revealed substantial population sub-

63 structuring (Baratti, Filippelli \& Messana 2011; Baratti, Goti \& Messana 2005; Carvalho \&

64 Piertney 1997; Hurtado, Mateos \& Santamaria 2010; Lessios \& Weinberg 1994; Markow \&

65 Pfeiler 2010; Raupach et al. 2007; Raupach \& Wägele 2006; Sponer \& Lessios 2009; Xavier et

al. 2011), as well as microgeographic variation in some intertidal species with specialist habitat

67 requirements (Carvalho 1989; Jolly, Rogers \& Sheader 2003; Piertney \& Carvalho 1994).

However, population genetics of the New Zealand marine Isopoda has been overlooked and little is known of isopod dispersal dynamics around New Zealand.

Here, we provide an exploratory investigation of the genomic variation present within and between populations and colour morphs of a highly polychromatic New Zealand marine isopod, Isocladus armatus (Sphaeromatidae). The endemic I. armatus is abundant in intertidal rock pools on semi-sheltered shores throughout New Zealand. I. armatus presents an interesting case study for dispersal because, unlike other direct developing marine invertebrates studied in New Zealand (Knox, Hogg \& Pilditch 2011; Sponer \& Roy 2002; Stevens \& Hogg 2004), they are neither restricted by fragmentary estuarine habitats, nor by sedentary life histories. They are strong swimmers that are able to navigate their position in a water column (Morton \& Miller 1968). However, it is currently unclear whether this mobility enhances or reduces population genetic stratification. For example, this swimming ability could either enable them to resist 
80 displacement during turbulent tidal movements as suggested by Jansen (1968), or alternatively,

81 to disperse substantial distances along the coast. Regardless, their widespread distribution

82 throughout New Zealand and the Chatham Islands suggests that their dispersal ability can be

83 substantial.

84 I. armatus displays extreme colour polymorphism (CP) within populations (Fig. 1). Whilst

85 colouration varies across an almost continuous scale, certain colour morphs, observable

86 throughout the species' geographic range (Jansen 1968), can be visually identified within this

87 continuum (Fig. 1). Although the evolutionary drivers of CP in I. armatus are unknown, CP is

88 generally presumed to have a genetic basis (Wellenreuther, Svensson \& Hansson 2014).

89 Moreover, previous studies of the genetic association of pigmentation in Sphaeromatid isopods

90 indicate that CPs are controlled by dominant alleles expressed at autosomal loci that are at low

91 frequencies in the population (Hedgecock, Tracy \& Nelson 1982; Shuster 1989). Although the

92 extreme CP in I. armatus indicates a probable polygenic basis to colouration, it is likely that at

93 least some of the more simple polymorphisms (such as presence/absence of a white dorsal stripe

94 (Fig. 1f \&g)) are controlled by one, or a few, loci (e.g. Sassaman and Garthwaite 1980). The

95 extreme CP in I. armatus suggests its potential as a tractable system for understanding how

96 genetic variation is maintained within populations. However, prior knowledge of the genetic

97 basis of colouration, as well as population connectivity in this system, is crucial.

98 Our study has two main objectives. First, we examine population structure and gene flow in $I$.

99 armatus at two different spatial scales to validate the use of genotyping-by-sequencing (GBS)

100 (Elshire et al. 2011) in investigating fine-scale and broad-scale dispersal in non-model marine

101 species. To date, most studies of marine organisms have used microsatellites, or mitochondrial or

102 nuclear DNA sequences to infer gene flow. However, single nucleotide polymorphisms (SNPs), 
103 abundantly and broadly distributed throughout the genome, can now provide a more thorough, 104 genome-wide insight into genetic variation. In particular, reduced representation techniques such 105 as GBS make it possible to genotype thousands of SNPs at relatively low costs in non-model 106 species for which there is no reference genome available (Davey et al. 2011). Second, because 107 information on the underlying genetic basis of colouration is critical to understanding how CP is 108 maintained in this system, we conduct $\mathrm{F}_{\mathrm{ST}}$ outlier tests of selection on this genomic data to 109 determine if any loci present in our dataset are putatively associated with colour. This validation 110 will form a basis for future studies to further resolve gene flow across multiple spatial scales, in 111 combination with a detailed investigation of the naturally occurring phenotypic variability in this 112 system.

\section{METHODS}

\section{Sample collection}

115 To investigate population connectivity at two different spatial scales, we collected 31-32 isopods

116 from two North Island populations $8 \mathrm{~km}$ apart (Hatfield's Beach and Stanmore Bay Beach north

117 of Auckland), and one South Island population (Kaikoura) around 1,000 km away (Fig. 2). From

118 each location we aimed to collect an equal number of males and females. We collected 119 approximately equal numbers of individuals of the four most easily classifiable morphotypes 120 from each population: variegated, striped, (Jansen 1968), white, and no-pattern (Fig. 1). No121 pattern individuals were mostly plain brown or orange. However, within all morphotypes there 122 was some additional variation in mottling or colour that was not assessed. Thus our morphs only 123 capture the most apparent variations present in this species. All individuals whose morphotype 
124 could not be unambiguously assigned were excluded from the colour analyses $(\mathrm{N}=12)$. Final

125 numbers of each morph and population are listed in Table 1. Collected isopods were put into ice

126 cold $70 \%$ ethanol and stored at $-30{ }^{\circ} \mathrm{C}$ until extraction. All sample collection has been approved

127 by a Ministry of Primary Industries New Zealand Special Permit 632.

129 Total genomic DNA was isolated from the head and pereopods of each sample. All DNA 130 extractions were preceded by a step to deactivate nucleases modified from a protocol for bone 131 samples in Edson et al. (2004). In this step, the head and pereopods of an individual were 132 homogenised using a plastic pestle in a $1.5 \mathrm{~mL}$ Eppendorf tube in a $65^{\circ} \mathrm{C}$ pre-heated solution 133 consisting of $15 \mathrm{~mL}$ of $0.5 \mathrm{M}$ EDTA $\mathrm{pH} 7.5$ per gram of sample to be digested, and $125 \mu \mathrm{L}$ of 20 $134 \%$ SDS per $1 \mathrm{~mL}$ of EDTA used. This was incubated and gently agitated overnight in an

135 Eppendorf Thermomixer $\mathrm{C}$ at $65^{\circ} \mathrm{C}$. Following this step, total genomic DNA was isolated using 136 a modified QIAgen DNeasy Blood and Tissue extraction protocol. The total volume of ATL 137 buffer was increased to a ratio of no less than 2 parts ATL buffer to 1 part EDTA solution, and 138 left to incubate overnight on a thermomixer at $65^{\circ} \mathrm{C}$ instead of $56^{\circ} \mathrm{C}$. Two volumes of $12 \mu \mathrm{L}$ 139 Proteinase $\mathrm{K}$ were added to the lysis solution at least two hours apart. Total yields of genomic 140 DNA were quantified using a Quantifluor ST fluorometer.

141 SNP genotyping

142 DArTseq $^{\mathrm{TM}}$ represents a combination of a DArT complexity reduction methods and next143 generation sequencing platforms (Courtois et al. 2013; Cruz, Kilian \& Dierig 2013; Kilian et al. 144 2012; Raman et al. 2014). Therefore, DArTseq ${ }^{\mathrm{TM}}$ represents a new implementation of 
145 sequencing of complexity reduced representations (Altshuler et al. 2000) and more recent

146 applications of this concept on the next generation sequencing platforms (Baird et al. 2008;

147 Elshire et al. 2011). Similarly to DArT methods based on array hybridisations, the technology is

148 optimized for each organism and application by selecting the most appropriate complexity

149 reduction method (both the size of the representation and the fraction of a genome selected for

150 assays). The PstI-SphI complexity reduction method was selected for our data. DNA samples

151 were processed in digestion/ligation reactions principally as per Kilian et al. (2012) but replacing

152 a single PstI-compatible adaptor with two different adaptors corresponding to two different

153 Restriction Enzyme (RE) overhangs. The PstI-compatible adapter was designed to include

154 Illumina flow cell attachment sequence, sequencing primer sequence and "staggered", varying

155 length barcode region, similar to the sequence reported by Elshire et al. (2011). The reverse

156 adapter contained flow cell attachment region and SphI-compatible overhang sequence. Only

157 "mixed fragments" (PstI-SphI) were effectively amplified in 30 rounds of PCR using the

158 following reaction conditions: $94{ }^{\circ} \mathrm{C}$ for 1 minute followed by 30 cycles of $94{ }^{\circ} \mathrm{C}$ for 20 seconds,

$15958{ }^{\circ} \mathrm{C}$ for 30 seconds, and $72{ }^{\circ} \mathrm{C}$ for 45 seconds, with a final extension of $72{ }^{\circ} \mathrm{C}$ for seven

160 minutes. After PCR, equimolar amounts of amplification products from each sample of the 96-

161 well microtiter plate were bulked and applied to cBot (Illumina) bridge PCR followed by

162 sequencing on Illumina Hiseq2500. The sequencing (single read) was run for 77 cycles.

163 Sequences generated from each lane were processed using proprietary DArT analytical pipelines.

164 In the primary pipeline the FASTQ files were first processed to filter out poor quality sequences, 165 applying more stringent selection criteria to the barcode region compared to the rest of the 166 sequence. In that way the assignments of the sequences to specific samples carried in the 167 "barcode split" step were very reliable. Finally, identical sequences are collapsed into "fastqcall 
168 files". These files are used in the secondary pipeline for DArT PL's proprietary SNP and

169 SilicoDArT (presence/absence of restriction fragments in representation) calling algorithms

170 (DArTsoft14).

171 SNP filtering

172 The DArTseq GBS data resulted in a dataset of 26,215 loci. All putative SNPs possessed only

173 two alleles. Further quality control filtering (Table S1) was applied to these loci in VCFtools

174 v.0.1.13 (Danecek et al. 2011) to prepare the data for population genetic analyses. Only SNPs

175 with a call rate (proportion of "missingness" across samples) $\geq 0.8$ across all individuals were

176 selected for further analysis. We retained loci with mean read depths of $\geq 5 X$ across individuals,

177 in order to eliminate loci where both alleles could not reliably be called. It has been

178 demonstrated that low frequency alleles can create biases in population genetic analyses and tests

179 of selection (Roesti et al. 2012). Therefore, we removed SNPs with a minor allele frequency

$180(\mathrm{MAF})<0.05$ both within a population, and SNPs with an average MAF $<0.05$ across the whole

181 dataset (Chakraborty et al. 1980; Clark et al. 1981). We also removed loci with observed

182 heterozygosities $>0.5$ which could represent potential homeologs (Hohenlohe et al. 2011).

183 Finally, potentially linked loci were removed by retaining only the SNP with greatest frequency

184 of heterozygotes from each sequence clone. For those analyses (STRUCTURE, MIGRATE)

185 which assume Hardy-Weinberg equilibrium (HWE), we also removed loci displaying significant

186 deviations $(\mathrm{p}<0.01)$ from HWE in one or more populations.

187 Prior to all population analyses, loci potentially under either balancing or divergent selection

188 were also removed (Table S1) as these "outlier" loci can produce different genetic signatures to 
189 neutral loci and bias estimates of population connectivity (Beaumont \& Nichols 1996; Luikart et

190 al. 2003). However, these loci were retained in analyses aiming to detect loci under selection for

191 colouration. Locus-specific departures from neutrality were assessed using two outlier F $_{\mathrm{ST}}$

192 methods. First, we employed the FDIST approach in ARLEQUIN. This method uses simulations

193 to generate a null distribution of $F$-statistics, in which $P$-values are conditioned on observed

194 levels of heterozygosities across loci (Excoffier, Hofer \& Foll 2009). We used the hierarchical

195 island model (Excoffier, Hofer \& Foll 2009) with the North Island populations in group one and

196 the Kaikoura population in group two. The hierarchical nature of this analysis takes into

197 consideration asymmetric migration rates between populations due to spatial structuring or

198 different population histories (Excoffier, Hofer \& Foll 2009). The analysis was carried out

199 assuming 10 groups of 100 demes with 50,000 simulated loci. Loci were deemed under selection

200 if they displayed a significant q-value after controlling for the False Discovery Rate (FDR)

201 according to Storey \& Tibshirani (2003). The FDR-adjusted q-values (FDR 5\%) were calculated

202 using the $\mathrm{R}$ package qvalue. The q-value of a locus defines the expected proportion of false

203 positives among all loci with P-values equal to or less than the observed locus (Storey \&

204 Tibshirani 2003). Second, we implemented a Bayesian approach in the program BayeScan (Foll

205 \& Gaggiotti 2008) which uses population-specific $\mathrm{F}_{\text {ST }}$ coefficients (Beaumont \& Balding 2004)

206 to calculate the posterior probability of a model including selection for each locus. The Bayesian

207 approach employed in BayeScan has been shown to provide more reliable estimates of selection

208 (Narum \& Hess 2011) due to the ability of posterior probabilities to correct for the identification

209 of false positives to a greater extent than Bonferroni corrections (Foll \& Gaggiotti 2008).

210 BayeScan was run using default parameters. From both analyses, loci displaying a q-value $\leq 0.05$

211 were conservatively excluded from further population genetic analyses (Table S1). 


\section{Genetic structure and gene flow between populations}

213 Global and per-locus observed heterozygosities, expected heterozygosities, and the population

214 coefficient of inbreeding $\left(\mathrm{F}_{\mathrm{IS}}\right)$ were estimated for each population in the $\mathrm{R}$ package diveRsity

215 using the function basicStats (Keenan et al. 2013). We used COANCESTRY (Wang 2011) to

216 estimate pairwise relatedness between North Island individuals in order to examine whether there

217 were any differences in relatedness within versus between North Island populations.

218 COANCESTRY was employed because it calculates relatedness based on seven different

219 estimators and allows the user to determine the most appropriate estimator to use for the data.

220 Because different marker-based relatedness estimators may perform better on different sets of

221 loci due to variation between population composition and allele frequencies (van de Casteele,

222 Galbusera \& Matthysen 2001), the most appropriate estimator to use for the data can be assessed

223 in COANCESTRY by conducting simulations based on the real data. The most suitable estimator

224 is that which produces relatedness values from simulations with the highest correlation

225 coefficient to the actual data (Wang 2011). TrioML, a maximum likelihood estimator was

226 deemed the most suitable estimator for our data $(r=0.998)$ and was used to estimate differences

227 in relatedness between groups. TrioML uses the genotype of a third individual as a reference in

228 estimating the pairwise genetic relatedness between dyads, reducing the chance that genes

229 identical in state are mistaken for genes that are identical by descent. We also used

230 COANCESTRY to assess whether the mean relatedness within the two North Island populations

231 is significantly different to the mean relatedness between the two North Island populations.

232 Significance was assessed by bootstrapping over individuals from both populations using 10,000

233 resamples. The difference in mean group relatedness was deemed statistically significant if it fell

234 outside the 2.5 and 97.5 percentiles generated by the permuted distribution $(\alpha=0.05)$. 
235 To quantify levels of genetic differentiation between populations, we calculated an unbiased

236 estimator of pairwise $\mathrm{F}_{\mathrm{ST}}$ (Weir \& Cockerham 1984) using the function pp.fst in the R package

237 hierfstat (Goudet 2005). The significance of these observed values was assessed by

238 bootstrapping over 10,000 replicates and calculating 95\% confidence intervals of these $\mathrm{F}_{\mathrm{ST}}$

239 estimates using the function boot.ppfst.

240 We conducted Principal Coordinates Analysis (PCA) in the R package SNPRelate (Zheng et al.

241 2012) to visualise any genetic structure present in the dataset. PCA constructs low dimensional

242 data projections with the aim of maximising the variance-covariance structure present among

243 sampled genotypes. We conducted PCA on both the North Island dataset, as well as on all

244 populations combined. A locus-by-locus hierarchical analysis of molecular variance (AMOVA)

245 was performed in ARLEQUIN v.3.5.2.2 (Excoffier, Smouse \& Quattro 1992; Michalakis \&

246 Excoffier 1996) with the two North Island populations grouped together to partition the total

247 genetic variance among groups (North Island and South Island), among populations within

248 groups (Hatfields Beach and Stanmore Bay), and within populations. Hierarchical AMOVA

249 computations were also conducted using the amova function in the R package pegas (Paradis

250 2010). This function requires as input a dist object representing a pairwise genetic distance

251 matrix. We used the bitwise.dist function in the poppr package (Kamvar, Brooks \& Grünwald

252 2015; Kamvar, Tabima \& Grünwald 2014) to produce a dissimilarity matrix based on the

253 fraction of different sites between sample genotypes according to Prevosti's distance (Prevosti,

254 Ocana \& Alonso 1975).

255 The number of genetic clusters $(\mathrm{K})$ was inferred from individual assignments under a Bayesian

256 framework implemented in STRUCTURE v.2.3.4 (Pritchard, Stephens \& Donnelly 2000). We

257 ran the program with all populations, and then with the North Island populations only to confirm 
258 that any potential hierarchical signatures of population differentiation were not obscuring any

259 weaker structuring that could be present in the North Island populations (Puechmaille 2016). We

260 ran the North Island analysis with information on sample location (LOCPRIOR model) included

261 as a prior (Hubisz et al. 2009). These priors can be useful when location information is

262 informative about true population clustering. This model uses information on the sampling

263 locations to help tease out weak genetic structuring that STRUCTURE's conservative algorithms

264 might otherwise overlook, without being predisposed to identifying structure where there is

265 actually none present. All models were run using a genetic admixture model and assuming

266 correlated allele frequencies between populations. We specified $\mathrm{K}=1$ to $\mathrm{K}=5$ to be tested for

267 the analysis with all three populations, and $K=1$ to $K=4$ to be tested for the analysis of two

268 North Island populations only. Markov Chain Monte Carlo simulations were run for 100,000

269 iterations with a 50,000 burnin and 10 independent replicates. Assignment of individuals to

270 clusters was inferred based on the inspection of a bar plot arising from the consolidation of

271 results over the 10 replicates of K produced in CLUMPP (Jakobsson \& Rosenberg 2007) and

272 visualised using DISTRUCT (Rosenberg 2004). Optimal values of K were selected following the

273 method of Evanno, Regnaut \& Goudet (2005) in STRUCTURE HARVESTER (Earl \& vonHoldt

274 2012) which uses the change in log likelihoods between STRUCTURE results produced at

275 different simulated $\mathrm{K}$ to infer the true $\mathrm{K}$.

276 We used a randomly generated subset of 1000 loci to investigate migration $(\mathrm{M}=\mathrm{m} / \mu$ where $\mathrm{m}=$

277 immigration rate per generation and $\mu=$ mutation rate per site) between populations using

278 coalescent modelling in MIGRATE (Beerli \& Felsenstein 2001). Due to the potentially large

279 orders of magnitude difference in gene flow between the North Island populations and between

280 the North and South Island populations, two analyses of migration were performed: the first 
281 investigated migration between Hatfield's Beach and Stanmore Bay, and the second between the

282 North Island populations (Hatfield's Beach and Stanmore Bay combined) and South Island. For 283 each analysis, we used a Bayesian Markov Chain Monte Carlo approach to investigate the 284 probabilities of three different nested models based on alternative migration scenarios: 1) 285 unidirectional gene flow from population 1 into population 2; 2) unidirectional gene flow from 286 population 2 into population 1; and 3) bidirectional gene flow between the two populations 287 allowing for asymmetric migration rates. Initial runs starting with mutation-scaled prior 288 parameters for population size $(\theta)$ and the migration rate $(\mathrm{M})$ based on $\mathrm{F}_{\mathrm{ST}}$ values produced good 289 posterior distributions, thus the mean values of 0.1 and 2500 on the priors for $\theta$ and $\mathrm{M}$ 290 respectively were used in further analyses. We employed Metropolis sampling with a static 291 heating scheme with four chains set at the default values, and ran each model for 1 million 292 generations with 20 replicate chains sampling every 100 steps (to produce 20 million 293 generations) with a burnin of 200,000 steps. Bayes factors were used to select the most 294 appropriate model for the data (Beerli 2006; Beerli \& Palczewski 2010).

$295 F_{S T}$ outlier tests

296 Outlier $\mathrm{F}_{\mathrm{ST}}$ tests were used to identify putative loci under selection and to investigate if any SNP 297 loci are associated with a gene coding for colour. We conducted non-hierarchical tests of 298 selection using morphotype as the grouping factor in Arlequin and BayeScan. Analyses were 299 conducted for all populations together and for the North Island populations only, with the 300 settings for the analyses the same as detailed above for the outlier analyses by population. We 301 considered loci under potential selection to be those with a q-value of 0.05 or less (Storey \& 302 Tibshirani 2003). 


\section{RESULTS}

304

305

306

307

308

309

310

311

312

313

314

315

316

317

318

319

320

321

322

323

324

\section{Genetic structure and gene flow between populations}

Of the 5,236 SNPs in our dataset, 2,461 of these were fixed for one island while being polymorphic for the other island. Of these 2,461 SNPs, 1,822 were fixed in the Kaikoura population, with the remainder being fixed in one, or both, of the North Island populations. This resulted in lower levels of observed heterozygosity in Kaikoura than in the North Island populations (Table 2, Fig.3a). Inbreeding coefficient values were slightly lower in Kaikoura (Table 2, Fig.3b). This is likely caused by greater habitat fragmentation (small rock platforms interspersed among sandy beaches) in the North Island populations than in the Kaikoura population (extended areas of intertidal rock platforms), which meant that isopods from the North Island sites were collected over smaller collection areas. Similarly, individual pairwise relatedness values were slightly lower for Kaikoura than for the North Island, although all values were generally low (Table 2). Mean pairwise relatedness between Hatfield's Beach and Stanmore Bay individuals $(r=0.0174)$ was not significantly different to the mean relatedness within populations $(\mathrm{r}=0.0171)$.

Different approaches to resolving population structure were in close agreement: all analyses indicated very little genetic differentiation between the two North Island populations, but large and significant differentiation between the North Island and South Island. $\mathrm{F}_{\mathrm{ST}}$ indices indicated strong population divergence both globally $\left(\mathrm{F}_{\mathrm{ST}}=0.31 \mathrm{p}<0.0001\right)$, and between the Hatfield's Beach and Kaikoura $\left(\mathrm{F}_{\mathrm{ST}}=0.42 \mathrm{p}<0.0001\right)$, and Stanmore Bay and Kaikoura $\left(\mathrm{F}_{\mathrm{ST}}=0.42 \mathrm{p}<\right.$ 0.0001). In contrast, no genetic differentiation was identified between the North Island populations $\left(\mathrm{F}_{\mathrm{ST}}<0.0001, \mathrm{p}=1.0\right)$. A PCA of genetic distances revealed a clear genetic 
325 distinction between North Island and South Island populations, with the first principal 326 component (PC) explaining $27.8 \%$ of the total variance and only $1.2 \%$ of the variance explained

327 by the second PC (Fig. 4a). In contrast, a PCA for the two North Island populations did not 328 further resolve population groupings, with PC1 and PC2 each explaining only $2.1 \%$ of the 329 variance (Fig. 4b).

330 Hierarchical AMOVA analysis in Arlequin was concordant with the PCA and showed that $33139.8 \%$ of the genetic variation occurred between the North and South Island groups and 59.9\% 332 within populations. In contrast, genetic variance between the North Island populations explained 333 only $0.3 \%$ of the total variance. The genetic structure found between populations $\left(\mathrm{F}_{\mathrm{ST}}=0.40, \mathrm{p}<\right.$ $3340.0001)$ and between groups $\left(\mathrm{F}_{\mathrm{CT}}=0.6, \mathrm{p}<0.0001\right)$ was strong and directly comparable. No 335 significant genetic structure was identified between the North Island populations $\left(\mathrm{F}_{\mathrm{SC}}=0.004, \mathrm{p}\right.$ $336=0.6$ ). The amova function in the $\mathrm{R}$ package pegas produced similar results with the variance 337 among groups accounting for $68.1 \%$ of the total variance $(\mathrm{p}<0.0001)$, while the variance within 338 groups accounted for only $0.19 \%$ of the total variance $(\mathrm{p}=0.9)$.

Bayesian clustering analysis identified strong genetic structuring between the North and South Island populations with strong support for $\mathrm{K}=2$ (Fig. 5a). No apparent genetic structure was present between Hatfield's Beach and Stanmore Bay. To be confident that strong hierarchical structure between the North and South Island was not obscuring any potential to identify weak structure in the North Island populations, we re-ran the analysis without the Kaikoura population

344 using the LOCPRIOR model for weak genetic structuring. However, $\mathrm{K}=2$ was not supported by 345 this analysis (Fig. 5b). Although $\Delta \mathrm{K}$ suggested that the true $\mathrm{K}$ was four (Figure $\mathrm{S} 1$ ), this statistic 346 is unable to find the best $\mathrm{K}$ when true $\mathrm{K}=1$ (Evanno, Regnaut \& Goudet 2005), and inspection 347 of the barplot of $K=4$ did not reveal any genetic clustering (Figure $\mathrm{S} 2$ ). Therefore, $\mathrm{K}=1$ for the 
348 North Island populations was inferred from the maximal mean log likelihood value for this $\mathrm{K}$

349 (Figure S3).

350 Patterns of gene flow between populations were inferred through model selection using Bayes

351 factors in MIGRATE. This analysis revealed that the model representing unidirectional gene

352 flow from the South Island into the North Island had the strongest support. The immigration rate

353 (M) of South Island individuals into the North Island was 88.3 (95\% Highest Posterior Density

354 (HPD): $3.3,166.7)$. When we considered only the two North Island populations, the full model

355 with bidirectional gene flow between the two populations provided the best fit. Estimated

356 migration rates were similar in both directions, with $\mathrm{M}=1271.7$ (95\% HPD: 1176.7, 1360.0)

357 from Stanmore Bay into Hatfields Beach, and $M=1205.0$ (95\% HPD: 1116.7, 1293.3) from

358 Hatfields Beach into Stanmore Bay (see Figures S4-S9 for posterior distributions of migration

359 parameters for each model).

360

$F_{S T}$ outlier tests

$361 \mathrm{~F}_{\mathrm{ST}}$ outlier tests of selection between morphotypes in BayeScan and Arlequin displayed very

362 similar results. Within the analysis of the North Island populations only, the same six loci were

363 identified as showing signatures of being under positive selection after controlling for the FDR in

364 both BayeScan and Arlequin (Table S2). Two of these loci were highly significant in both

365 analyses with q-values of zero. When all populations were considered, four loci were deemed

366 under selection for morphotype after controlling for the FDR in both analyses (Table S2). This

367 included the two highly significant loci from the North Island analysis. Visual inspection of the

368 genotypes of these two loci revealed that the existence of at least one non-reference SNP allele at

369 these loci was associated with the expression of the striped morph in all striped individuals from

370 all populations $(\mathrm{N}=13)$, apart from one individual with an uncommon striped pattern from 
371 Stanmore Bay (Fig. 1g). No individuals of other morphotypes possessed SNP alleles at these 372 loci.

373 A PCA of genetic distances for the North Island populations using all loci and with individuals 374 coloured by morphotype did not reveal any substantial clustering by morph (Figure S10).

375 However, PCA for the North Island populations using only the six SNPs deemed under selection 376 revealed substantial clustering by morphotype (Fig. 6). This clustering was particularly apparent

377 for the striped morph. The first and second principal components explained $41.1 \%$ and $23.9 \%$ 378 of the total variance respectively. PCA analysis was not conducted with the four loci under 379 putative selection identified when all three populations are included, because a minimum of five 380 loci are needed for SNPRelate to run.

\section{DISCUSSION}

382

This study is one of the first population genomic studies on a marine organism in New Zealand. Using GBS, we were able to obtain a substantially large number $(4,000-5,000)$ of high quality SNPs. Our results show evidence of highly contrasting levels of population connectivity and gene flow associated with different spatial scales in I. armatus. We also identified several loci that are under putative selection for colour. Our findings provide a strong case that reducedrepresentation genomic capabilities can efficiently resolve both neutral and non-neutral genetic variation in species inhabiting the dynamic marine environment, and for which there is no reference genome.

\section{Population connectivity and gene flow}

In order to glean deep insight into the processes influencing genetic variation within and between populations, the geographical scale of population sampling regimes should equate to the scale at 
393 which dispersal occurs (Broquet \& Petit 2009). By using a large SNP dataset and sampling

394 across two contrasting spatial scales, we successfully identified a scale below which population

395 differentiation is not apparent, and a scale at which population differentiation is clearly defined.

396 While we cannot completely rule out the possibility that our SNP dataset was unable resolve

397 fine-scale population structuring (DeFaveri et al. 2013; Hess, Matala \& Narum 2011), we

398 consider this scenario unlikely due to the large number of SNP markers used in our study (Gärke

399 et al. 2012; Haasl \& Payseur 2011; Morin, Martien \& Taylor 2009).

400 Direct development is purported to limit isopod dispersal and drive strong genetic differentiation 401 among populations inhabiting the same coastlines (Baratti, Filippelli \& Messana 2011; Carvalho 402 \& Piertney 1997; Hurtado, Mateos \& Santamaria 2010; Lessios \& Weinberg 1994; Markow \& 403 Pfeiler 2010; Sponer \& Lessios 2009; Xavier et al. 2011). Microgeographic genetic variation has 404 been recorded in isopods, particularly in species exhibiting habitat fragmentation and limited 405 vagility (Jolly, Rogers \& Sheader 2003; Piertney \& Carvalho 1994). For example, in Jaera 406 albifrons, significant differentiation occurs across five metre distances due to the patchy 407 distribution of suitable habitats (Piertney \& Carvalho 1994). In I. armatus we hypothesised that 408 we would see low, but significant, levels of genetic variation between two North Island 409 populations $8 \mathrm{~km}$ apart. Instead, we found no evidence of genetic structuring between these 410 populations, with all analyses indicating panmixia. There was also no difference in mean 411 pairwise genetic relatedness within or between the North Island populations, suggesting that 412 there is no decline in dispersal rates with distance between the two sites. Although little is known 413 of the dispersal abilities of marine isopods around the New Zealand coastline, McGaughran et al. 414 (2006) found no evidence of population subdivision in three species of coastal stream-dwelling 415 isopod, Austridotea spp, along the east coast of the South Island. Thus it appears that New 
416 Zealand isopods are capable of substantial levels of dispersal along coastlines, despite their

417 sedentary reproductive histories. It is worth noting that both the estuarine Austridotea and marine

418 Isocladus can, and often, swim. Thus it is probable that this mobility, in combination with

419 displacement driven by surface storm events, facilitates dispersal along coastlines.

420 In strong contrast to the North Island, population differentiation between Kaikoura and the two

421 North Island populations was extreme, indicating very little gene exchange between the North

422 and South Islands. Migration rates (M) between the North and South Island were 14 x smaller

423 than those between the North Island populations. Estimates of $\mathrm{M}$ can be converted to number of

424 effective migrants per generation $(\mathrm{Nm})$ using the equation $\chi N \mathrm{Nm}=\Theta_{\mathrm{i}} \times \mathrm{M}_{\mathrm{i} \rightarrow \mathrm{j}}$ in which $\Theta=\mathrm{Ne} \mu$;

425 where $\mathrm{Ne}=$ the effective population size, and $\mu=$ mutation rate per generation per locus). This

426 equates to around 31 (95\% Highest Posterior Density (HPD): 27, 35) migrants per generation in

427 each direction between North Island populations, and 2.1 (95\% HPD: 0.07, 4.13) migrants per

428 generation between the North and South Island populations. These values are consistent with

429 values of Nm estimated at two similar spatial scales in other direct developing marine

430 invertebrates; the scleractinian Balanophyllia elegans (Hellberg 1995), and Ototyphlonemertes

431 spp.(Andrade et al., 2011).

432 However, estimates of gene flow produced in MIGRATE should be treated with caution for 433 several reasons. First, care is needed in interpreting $\mathrm{Nm}$ because of the potential uncertainty in 434 the effective population size indicated by $\Theta$. Second, MIGRATE does not currently consider a 435 model of zero migration. Given our other results, and that the range of the North-South HPD 436 intervals almost overlap zero, this might be the most plausible scenario for the North and South 437 Island. Similarly, it is important to note that the North Island analysis does not distinguish 438 between the full model and panmixia, which could be a more appropriate model given our data. 
439 Third, because MIGRATE assumes that populations have been in equilibrium for $\sim 4 \mathrm{~N}$

440 generations (Kingman 1982), shared ancestry associated with recent population splits will lead to

441 inflated estimates of gene flow (Kuhner 2009). This is likely to be particularly relevant for the

442 North Island migration estimates. Fourth, migration rates are assumed to be temporarily stable

443 and are calculated across time to the most recent common ancestor. Therefore, estimated

444 migration rates may reflect historical, rather than contemporary, gene flow (e.g. Marko \& Hart 445 2011).

446 Patterns of gene flow in the marine environment can be influenced by oceanographic features 447 such as biogeographical boundaries and patterns of coastal circulation (Bilton, Paula \& Bishop 448 2002; Perrin, Wing \& Roy 2004; Ross et al. 2009; Wares, Gaines \& Cunningham 2001; White et al. 449 2010). It remains to be determined whether gene flow between Auckland and Kaikoura is 450 interrupted by the presence of geophysical barriers, or whether populations follow a graduated 451 model of dispersal, such as that exhibited by isolation-by-distance and stepping stone models.

452 Nevertheless, the genetic subdivision present in I. armatus is congruent with an observed main 453 break in the distribution of Sphaeromatidae species, with many North and South Island species 454 displaying their geographical limits in the Kaikoura region (Hurley \& Jansen 1977). 455 Furthermore, this break coincides with a defined boundary between the two main New Zealand 456 marine biogeographic regions based on macroalgal and macroinvertebrate taxa (Shears et al. 457 2008). This evidence suggests that there may be a geophysical barrier present near Kaikoura 458 which poses a barrier to gene flow between North and South Island marine communities.

459 This north-south phylogenetic subdivision is a common finding emanating from marine 460 population genetics studies in New Zealand (Apte \& Gardner 2002; Ayers \& Waters 2005;

461 Goldstien, Schiel \& Gemmell 2006; Hickey et al. 2009; Keeney, Szymaniak \& Poulin 2013; 
462 Ross et al. 2012; Sponer \& Roy 2002; Veale \& Lavery 2011; Waters \& Roy 2004), particularly

463 down the east coast of New Zealand where currents are stronger than on the west (Heath 1985;

464 Stanton 1976). Previous work in direct developing marine invertebrates suggests that ocean

465 currents and upwelling regions (Fig. 2b) associated with the north-eastern coast of the South

466 Island (Sponer \& Roy 2002; Keeney, Szymaniak \& Poulin 2013), or East Cape (Knox, Hogg \&

467 Pilditch 2011; Stevens \& Hogg 2004; Veale \& Lavery 2012) could be responsible for these sharp

468 genetic disjunctions. Although our current data do not allow us to identify the location of the

469 genetic break, our study suggests that a strong barrier to gene flow is present between Auckland

470 and Kaikoura, and advocates for future intensive sampling between these two sites. If these

471 intermediate sites are combined with a hierarchical sampling regime that includes populations

472 sampled across staggered spatial scales, I. armatus' capacity for dispersal, as well as the

473 influence of any hydrographic features on gene flow, can be determined.

474 Similar to findings in other intertidal and deep-sea isopods (e.g. Baratti, Filippelli \& Messana

475 2011; Raupach et al. 2007; Sponer \& Lessios 2009; Xavier et al. 2011), the strong genetic

476 divergence between the North and South Island populations alludes to the possible existence of

477 cryptic species. Sanger sequencing of the cytochrome c oxidase subunit 1 mitochondrial gene

478 should be conducted to assess this possibility (Lefébure et al. 2006).

479 If I. armatus does indeed represent a cryptic species complex, the evolutionary persistence of 480 morphotypes across speciation events suggests that polychromatism in I. armatus is likely 481 maintained by selection. The alternative-that shared polychromatism is due to demographic 482 processes such as the retention of ancestral polymorphisms or introgression-is unlikely since we 483 found no evidence of genetic admixture within North and South Island individuals, and given the 484 large number of SNPs that were fixed within North and South Island populations. However, 
485 further refinement of rates of gene flow and analysis of divergence times between the two main 486 islands would help distinguish between these processes.

\section{Genetic basis of colouration}

488 We found possible evidence of a genetic basis to CP. Six SNPs were deemed to be associated 489 with, or are in linkage disequilibrium with, a gene that is under putative positive selection for 490 morphotype. Of these six SNPs, two showed evidence of an association to the expression of the 491 striped morph. Our findings suggest that there may be more than one locus controlling the 492 phenotypic expression of the white stripe because one striped morph with an uncommon 493 patterning and less-defined stripe did not possess the SNP allele at these loci. Although the 494 diverse colouration in I. armatus suggests that the genetic basis of colouration in this species is likely to be complex, our findings suggest that at least some polymorphisms may be controlled 496 by a relatively small number of loci (e.g. Sassaman \& Garthwaite 1980), and that their effects on 497 phenotype could be additive. In order to confirm a genetic basis to polychromatism in I. armatus, 498 our analyses require verification with larger sample sizes for each morph, accompanied by 499 captive breeding experiments based on Mendelian genetics. Presently, the adaptive function of colouration in I. armatus is unknown. In isopods, however, predation is a common driver of 501 stabilising selection on colouration (e.g. Jormalainen, Merilaita \& Tuomi 1995; Merilaita 2001), 502 which should fix colouration onto the single most efficiently cryptic phenotype for that 503 population. We know that small-scale variations in colour morph frequencies can occur in $I$. 504 armatus (Jansen 1971). Therefore, the high gene flow occurring at relatively small spatial scales

$505(<8 \mathrm{~km})$ demonstrated by our study suggests the existence of selective pressures that can 506 maintain CP within populations in this species. An integrated knowledge of population 507 connectivity with a detailed analysis of the naturally occurring selection associated with 
508 phenotypic variability is needed to identify the selective pressures acting on colouration. To

509 achieve this, gene flow will need to be resolved over more populations and compared with an

510 analysis of colour variation at each site.

\section{CONCLUSIONS}

512 Our study provides evidence that GBS can efficiently resolve both fine-scale and broad-scale 513 genetic structuring in a non-model vagile marine species. Our findings suggest that I. armatus

514 possesses substantial dispersal ability despite lacking a pelagic larval stage. However, in

515 accordance with studies in other New Zealand marine invertebrates, strong differentiation

516 between North and South Island populations suggests the presence of at least one barrier to gene

517 flow down the east coast of New Zealand. This study improves our understanding of the fine-

518 scale dispersal capabilities of marine invertebrates lacking a pelagic larval phase, and provides a 519 platform for further investigations into the role that gene flow plays in maintaining CP in this species.

\section{ACKNOWLEDGEMENTS}

521 We would like to acknowledge Landcare Research Ltd. and the University of Canterbury for 522 providing laboratory and field logistical support respectively. We are grateful to David Eme for

523 providing helpful suggestions and some of the scripts used in the analyses; and Libby Liggins 524 and David Aguirre for constructive advice on this project. Thanks also to Julia Allwood, Ana

525 Ramón-Laca, and Duckchul Park for laboratory advice and support. We thank Shane Lavery and 526 an anonymous reviewer for their invaluable reviews that improved this paper, and Peter Prentis 527 for his constructive comments as editor.

\section{REFERENCES}


529 Altshuler D, Pollara VJ, Cowles CR, and Van Etten WJ. 2000. An SNP map of the human 530 genome generated by reduced representation shotgun sequencing. Nature 407:513.

531 Andrade SC, Norenburg JL, and Solferini VN. 2011. Worms without borders: genetic diversity

532

533

534

535

536

537

538

539

540

541

542

543

544

545

546

547

548

549

550

551 patterns in four Brazilian Ototyphlonemertes species (Nemertea, Hoplonemertea). Marine Biology 158:2109.

Apte S, and Gardner J. 2002. Population genetic subdivision in the New Zealand greenshell mussel (Perna canaliculus) inferred from single-strand conformation polymorphism analysis of mitochondrial DNA. Molecular Ecology 11:1617-1628.

Ayers K, and Waters J. 2005. Marine biogeographic disjunction in central New Zealand. Marine Biology 147:1045-1052.

Baird NA, Etter PD, Atwood TS, Currey MC, Shiver AL, Lewis ZA, Selker EU, Cresko WA, and Johnson EA. 2008. Rapid SNP discovery and genetic mapping using sequenced RAD markers. PLoS ONE 3:e3376.

Baratti M, Filippelli M, and Messana G. 2011. Complex genetic patterns in the mangrove woodborer Sphaeroma terebrans Bate, 1866 (Isopoda, Crustacea, Sphaeromatidae) generated by shoreline topography and rafting dispersal. Journal of Experimental Marine Biology and Ecology 398:73-82.

Baratti M, Goti E, and Messana G. 2005. High level of genetic differentiation in the marine isopod Sphaeroma terebrans (Crustacea Isopoda Sphaeromatidae) as inferred by mitochondrial DNA analysis. Journal of Experimental Marine Biology and Ecology $315: 225-234$.

Barton NH, and Turelli M. 1989. Evolutionary quantitative genetics: how little do we know? Annual review of genetics 23:337-370. 
552 Beaumont MA, and Balding DJ. 2004. Identifying adaptive genetic divergence among

553

554

555

556

557

558

559

560

561

562

563

564

565

566

567

568

569

570

571

572

573 populations from genome scans. Molecular Ecology 13:969-980.

Beaumont MA, and Nichols RA. 1996. Evaluating loci for use in the genetic analysis of population structure. Proceedings of the Royal Society of London B: Biological Sciences 263:1619-1626.

Beerli P. 2006. Comparison of Bayesian and maximum-likelihood inference of population genetic parameters. Bioinformatics 22:341-345.

Beerli P, and Felsenstein J. 2001. Maximum likelihood estimation of a migration matrix and effective population sizes in $\mathrm{n}$ subpopulations by using a coalescent approach. Proceedings of the National Academy of Sciences 98:4563-4568.

Beerli P, and Palczewski M. 2010. Unified framework to evaluate panmixia and migration direction among multiple sampling locations. Genetics 185:313-326.

Benzie J. 2000. The detection of spatial variation in widespread marine species: methods and bias in the analysis of population structure in the crown of thorns starfish (Echinodermata: Asteroidea). Marine Genetics: Springer, 1-14.

Bilton D, Paula J, and Bishop J. 2002. Dispersal, genetic differentiation and speciation in estuarine organisms. Estuarine, Coastal and Shelf Science 55:937-952.

Brooks R. 2002. Variation in female mate choice within guppy populations: population divergence, multiple ornaments and the maintenance of polymorphism. Genetica 116:343-358.

Broquet T, and Petit EJ. 2009. Molecular estimation of dispersal for ecology and population genetics. Annual Review of Ecology, Evolution, and Systematics 40:193-216. 
574 Carvalho GR. 1989. Microgeographic genetic differentiation and dispersal capacity in the

575

576

577

578

579

580

581

582

583

584

585

586

587

588

589

590

591

592

593

594

595 intertidal isopod, Jaera albifrons Leach. In: Ryland JS, and Tyler PA, eds. Reproduction, Genetics and Distributions of Marine Organisms: 23rd European Marine Biology Symposium, School of Biological Sciences, University of Wales, Swansea. Fredensborg: Olsen \& Olsen.

Carvalho GR, and Piertney SB. 1997. Interspecific comparisons of genetic population structure in members of the Jaera albifrons species complex. Journal of the Marine Biological Association of the United Kingdom 77:77-93.

Courtois B, Audebert A, Dardou A, Roques S, Ghneim-Herrera T, Droc G, Frouin J, Rouan L, Gozé E, and Kilian A. 2013. Genome-wide association mapping of root traits in a japonica rice panel. PLoS ONE 8:e78037.

Cowen RK, and Sponaugle S. 2009. Larval dispersal and marine population connectivity. Annual Review of Marine Science 1:443-466.

Cruz VMV, Kilian A, and Dierig DA. 2013. Development of DArT marker platforms and genetic diversity assessment of the US collection of the new oilseed crop lesquerella and related species. PLoS ONE 8:e64062.

Danecek P, Auton A, Abecasis G, Albers CA, Banks E, DePristo MA, Handsaker RE, Lunter G, Marth GT, and Sherry ST. 2011. The variant call format and VCFtools. Bioinformatics 27:2156-2158.

Davey JW, Hohenlohe PA, Etter PD, Boone JQ, Catchen JM, and Blaxter ML. 2011. Genomewide genetic marker discovery and genotyping using next-generation sequencing. Nature Reviews Genetics 12:499-510. 
596 DeFaveri J, Viitaniemi H, Leder E, and Merilä J. 2013. Characterizing genic and nongenic

597

598

599

600

601

602

603

604

605

606

607

608

609

610

611

612

613

614

615

616

617

618 molecular markers: comparison of microsatellites and SNPs. Molecular Ecology Resources 13:377-392.

Earl DA, and vonHoldt BM. 2012. STRUCTURE HARVESTER: a website and program for visualizing STRUCTURE output and implementing the Evanno method. Conservation Genetics Resources 4:359-361.

Edson SM, Ross J, Coble M, Parson T, and Barritt S. 2004. Naming the dead-confronting the realities of the rapid identification of degraded skeletal remains. Forensic Science Review $16: 63-88$.

Elshire RJ, Glaubitz JC, Sun Q, Poland JA, Kawamoto K, Buckler ES, and Mitchell SE. 2011. A robust, simple genotyping-by-sequencing (GBS) approach for high diversity species. PLOS ONE 6:e19379.

Endler JA. 1986. Natural selection in the wild: Princeton University Press.

Evanno G, Regnaut S, and Goudet J. 2005. Detecting the number of clusters of individuals using the software STRUCTURE: a simulation study. Molecular Ecology 14:2611-2620.

Excoffier L, Hofer T, and Foll M. 2009. Detecting loci under selection in a hierarchically structured population. Heredity 103:285-298.

Excoffier L, Smouse PE, and Quattro JM. 1992. Analysis of molecular variance inferred from metric distances among DNA haplotypes: application to human mitochondrial DNA restriction data. Genetics 131:479-491.

Foll M, and Gaggiotti O. 2008. A genome-scan method to identify selected loci appropriate for both dominant and codominant markers: a Bayesian perspective. Genetics 180:977-993.

Ford EB. 1964. Ecological genetics. Ecological genetics. London: Methuen \& Co. 
619 Futuyma DJ. 2005. Evolution. Sunderland, MA: Sinauer Associates Inc.

620 Gärke C, Ytournel F, Bed'hom B, Gut I, Lathrop M, Weigend S, and Simianer H. 2012.

621 Comparison of SNPs and microsatellites for assessing the genetic structure of chicken

622 populations. Animal genetics 43:419-428.

623 Goldstien SJ, Schiel DR, and Gemmell NJ. 2006. Comparative phylogeography of coastal 624 limpets across a marine disjunction in New Zealand. Molecular Ecology 15:3259-3268.

625 Goudet J. 2005. Hierfstat, a package for R to compute and test hierarchical F-statistics.

$626 \quad$ Molecular Ecology Resources 5:184-186.

627 Haasl RJ, and Payseur BA. 2011. Multi-locus inference of population structure: a comparison

628 between single nucleotide polymorphisms and microsatellites. Heredity 106:158-171.

629 Hartl DL, and Clark AG. 1997. Principles of population genetics. Sunderland, MA: Sinauer $630 \quad$ associates Inc.

631 Heath R. 1985. A review of the physical oceanography of the seas around New Zealand-1982. 632 New Zealand Journal of Marine and Freshwater Research 19:79-124.

633 Hedgecock D, Tracy M, and Nelson K. 1982. Genetics. In: Abele LG, ed. The Biology of 634 Crustacea Vol 2 Embryology, Morphology, and Genetics. New York: Academic Press.

635 Hedrick PW. 1986. Genetic polymorphism in heterogeneous environments: a decade later. 636 Annual Review of Ecology and Systematics 17:535-566.

637 Hedrick PW. 2006. Genetic polymorphism in heterogeneous environments: the age of genomics. 638 Annual Review of Ecology Evolution and Systematics 37:67-93.

639 Hellberg M. 1995. Stepping-stone gene flow in the solitary coral Balanophyllia elegans: 640 equilibrium and nonequilibrium at different spatial scales. Marine Biology 123:573-581. 
641 Hess J, Matala A, and Narum S. 2011. Comparison of SNPs and microsatellites for fine-scale

642

643

644

645

646

647

648

649

650

651

652

653

654

655

656

657

658

659

660

661

662 application of genetic stock identification of Chinook salmon in the Columbia River Basin. Molecular Ecology Resources 11:137-149.

Hickey AJ, Lavery SD, Hannan DA, Baker CS, and Clements KD. 2009. New Zealand triplefin fishes (family Tripterygiidae): contrasting population structure and mtDNA diversity within a marine species flock. Molecular Ecology 18:680-696.

Hohenlohe PA, Amish SJ, Catchen JM, Allendorf FW, and Luikart G. 2011. Next-generation RAD sequencing identifies thousands of SNPs for assessing hybridization between rainbow and westslope cutthroat trout. Molecular Ecology Resources 11:117-122.

Hubisz MJ, Falush D, Stephens M, and Pritchard JK. 2009. Inferring weak population structure with the assistance of sample group information. Molecular Ecology Resources 9:13221332.

Hurley DE, and Jansen KP. 1977. The marine fauna of New Zealand: Family Sphaeromatidae (Crustacea Isopoda: Flabellifera). New Zealand Oceanographic Institute Memoir 63:1-80.

Hurtado LA, Mateos M, and Santamaria CA. 2010. Phylogeography of supralittoral rocky intertidal Ligia isopods in the Pacific region from central California to central Mexico. PLoS ONE 5:e11633.

Jakobsson M, and Rosenberg NA. 2007. CLUMPP: a cluster matching and permutation program for dealing with label switching and multimodality in analysis of population structure. Bioinformatics 23:1801-1806.

Jansen KP. 1968. A comparative study of intertidal species of Sphaeromidae (Isopoda Flabellifera) PhD. University of Canterbury, New Zealand. 
663 Jansen KP. 1971. Ecological studies on intertidal New Zealand Sphaeromatidae (Isopoda:

$664 \quad$ Flabellifera). Marine Biology 11:262-285.

665 Jolly MT, Rogers AD, and Sheader M. 2003. Microgeographic genetic variation of populations

666 of Idotea chelipes (Crustacea: Isopoda) in lagoons of the southern English coast. Cahiers

667 de Biologie Marine 44:319-327.

668 Jormalainen V, Merilaita S, and Tuomi J. 1995. Differential predation on sexes affects colour 669 polymorphism of the isopod Idotea baltica (Pallas). Biological Journal of the Linnean $670 \quad$ Society 55:45-68.

671 Kamvar ZN, Brooks JC, and Grünwald NJ. 2015. Novel R tools for analysis of genome-wide population genetic data with emphasis on clonality. Frontiers in Genetics 6.

673 Kamvar ZN, Tabima JF, and Grünwald NJ. 2014. Poppr: an R package for genetic analysis of 674 populations with clonal, partially clonal, and/or sexual reproduction. PeerJ 2:e281.

Kawecki TJ, and Ebert D. 2004. Conceptual issues in local adaptation. Ecology Letters 7:1225-

676 1241.

677

678

679

680

681

682

683

684
Keenan K, McGinnity P, Cross TF, Crozier WW, and Prodöhl PA. 2013. diveRsity: An R package for the estimation and exploration of population genetics parameters and their associated errors. Methods in Ecology and Evolution 4:782-788.

Keeney DB, Szymaniak AD, and Poulin R. 2013. Complex genetic patterns and a phylogeographic disjunction among New Zealand mud snails Zeacumantus subcarinatus and Z. lutulentus. Marine Biology 160:1477-1488.

Kilian A, Wenzl P, Huttner E, Carling J, Xia L, Blois H, Caig V, Heller-Uszynska K, Jaccoud D, and Hopper C. 2012. Diversity arrays technology: a generic genome profiling technology 

Protocols:67-89.

687

688

689

690

691

692

693

694

695

696

697

698

699

700

701

702

703

704

705

706

Kingman JFC. 1982. The coalescent. Stochastic processes and their applications 13:235-248.

Knox MA, Hogg ID, and Pilditch CA. 2011. The role of vicariance and dispersal on New Zealand's estuarine biodiversity: the case of Paracorophium (Crustacea: Amphipoda). Biological Journal of the Linnean Society 103:863-874.

Kotiaho JS, Simmons LW, and Tomkins JL. 2001. Towards a resolution of the lek paradox. Nature 410:684-686.

Kuhner MK. 2009. Coalescent genealogy samplers: windows into population history. Trends in Ecology \& Evolution 24:86-93.

Lefébure T, Douady C, Gouy M, and Gibert J. 2006. Relationship between morphological taxonomy and molecular divergence within Crustacea: proposal of a molecular threshold to help species delimitation. Molecular Phylogenetics and Evolution 40:435-447.

Lessios H, and Weinberg JR. 1994. Genetic and morphological divergence among morphotypes of the isopod Excirolana on the two sides of the Isthmus of Panama. Evolution:530-548.

Lewontin RC. 1974. The genetic basis of evolutionary change. New York: Columbia University Press

Luikart G, England PR, Tallmon D, Jordan S, and Taberlet P. 2003. The power and promise of population genomics: from genotyping to genome typing. Nature Reviews Genetics 4:981-994.

Marko PB, and Hart MW. 2011. The complex analytical landscape of gene flow inference. Trends in Ecology \& Evolution 26:448-456. 
707 Markow TA, and Pfeiler E. 2010. Mitochondrial DNA evidence for deep genetic divergences in

708 allopatric populations of the rocky intertidal isopod Ligia occidentalis from the eastern Pacific. Molecular Phylogenetics and Evolution 56:468-473.

710

711

712

713

714

715

716

717

718

719

720

721

722

723

724

725

726

727

728

McGaughran A, Hogg ID, Stevens MI, Lindsay Chadderton W, and Winterbourn MJ. 2006. Genetic divergence of three freshwater isopod species from southern New Zealand. Journal of Biogeography 33:23-30.

Merilaita S. 2001. Habitat heterogeneity, predation and gene flow: colour polymorphism in the isopod, Idotea baltica. Evolutionary Ecology 15:103-116.

Michalakis Y, and Excoffier L. 1996. A generic estimation of population subdivision using distances between alleles with special reference for microsatellite loci. Genetics 142:1061-1064.

Morin PA, Martien KK, and Taylor BL. 2009. Assessing statistical power of SNPs for population structure and conservation studies. Molecular Ecology Resources 9:66-73.

Morton J, and Miller M. 1968. The New Zealand sea shore. Auckland: Collins.

Narum SR, and Hess JE. 2011. Comparison of FST outlier tests for SNP loci under selection. Molecular Ecology Resources 11:184-194.

Nei M. 1975. Molecular population genetics and evolution: North-Holland Publishing Co.

Palumbi SR. 2004. Marine reserves and ocean neighborhoods: the spatial scale of marine populations and their management. Annual Review of Environment and Resources 29:3168.

Pamilo P. 1988. Genetic variation in heterogeneous environments. Annales Zoologici Fennici:99-106. 
729 Paradis E. 2010. pegas: an R package for population genetics with an integrated-modular $730 \quad$ approach. Bioinformatics 26:419-420.

731 Perrin C, Wing SR, and Roy MS. 2004. Effects of hydrographic barriers on population genetic 732 structure of the sea star Coscinasterias muricata (Echinodermata, Asteroidea) in the New

733

734

735

736

737

738

739

740

741

742

743

744

745

746

747

748

749

750 Zealand fiords. Molecular Ecology 13:2183-2195.

Piertney SB, and Carvalho GR. 1994. Microgeographic genetic differentiation in the intertidal isopod Jaera albifrons Leach. I. Spatial distribution of allozyme variation. Proceedings of the Royal Society of London B: Biological Sciences 256:195-201.

Prevosti A, Ocana J, and Alonso G. 1975. Distances between populations of Drosophila subobscura, based on chromosome arrangement frequencies. Theoretical and Applied Genetics 45:231-241.

Pritchard JK, Stephens M, and Donnelly P. 2000. Inference of population structure using multilocus genotype data. Genetics 155:945-959.

Puechmaille SJ. 2016. The program structure does not reliably recover the correct population structure when sampling is uneven: subsampling and new estimators alleviate the problem. Molecular Ecology Resources 16:608-627.

Raman H, Raman R, Kilian A, Detering F, Carling J, Coombes N, Diffey S, Kadkol G, Edwards D, and McCully M. 2014. Genome-wide delineation of natural variation for pod shatter resistance in Brassica napus. PLoS ONE 9:e101673.

Riginos C, Crandall ED, Liggins L, Bongaerts P, and Treml EA. 2016. Navigating the currents of seascape genomics: how spatial analyses can augment population genomic studies. Current Zoology : zow067. 
751 Raupach MJ, Malyutina M, Brandt A, and Wägele J-W. 2007. Molecular data reveal a highly

752 diverse species flock within the munnopsoid deep-sea isopod Betamorpha fusiformis

753

754 (Barnard, 1920)(Crustacea: Isopoda: Asellota) in the Southern Ocean. Deep Sea Research Part II: Topical Studies in Oceanography 54:1820-1830.

755

756

757

758 759

Raupach MJ, and Wägele J-W. 2006. Distinguishing cryptic species in Antarctic Asellota (Crustacea: Isopoda)-a preliminary study of mitochondrial DNA in Acanthaspidia drygalskii. Antarctic Science 18:191-198.

Rosenberg NA. 2004. DISTRUCT: a program for the graphical display of population structure. Molecular Ecology Notes 4:137-138.

Ross PM, Hogg ID, Pilditch CA, and Lundquist CJ. 2009. Phylogeography of New Zealand's coastal benthos. New Zealand Journal of Marine and Freshwater Research 43:10091027.

Ross PM, Hogg ID, Pilditch CA, Lundquist CJ, and Wilkins RJ. 2012. Population genetic structure of the New Zealand estuarine clam Austrovenus stutchburyi (Bivalvia: Veneridae) reveals population subdivision and partial congruence with biogeographic boundaries. Estuaries and Coasts 35:143-154.

Roulin A. 2004. The evolution, maintenance and adaptive function of genetic colour polymorphism in birds. Biological Reviews 79:815-848.

Sassaman C, and Garthwaite R. 1980. Genetics of a pigment polymorphism in the isopod Porcellio dilatatus. Journal of Heredity 71:158-160.

Shears NT, Smith F, Babcock RC, Duffy CA, and Villouta E. 2008. Evaluation of biogeographic classification schemes for conservation planning: Application to New Zealand's coastal marine environment. Conservation Biology 22:467-481. 
774 Shuster SM. 1989. Male alternative reproductive strategies in a marine isopod crustacean

775 (Paracerceis sculpta): the use of genetic markers to measure differences in fertilization

776 success among $\alpha-, \beta-$, and $\gamma$-males. Evolution:1683-1698.

777 Sponer R, and Lessios HA. 2009. Mitochondrial phylogeography of the intertidal isopod Excirolana braziliensis on the two sides of the Isthmus of Panama. Smithsonian Contributions to the Marine Sciences 38:219-228.

780

781

782

783

784

785

786

787

788

789

790

791

792

793

794

795

Sponer R, and Roy MS. 2002. Phylogeographic analysis of the brooding brittle star Amphipholis squamata (Echinodermata) along the coast of New Zealand reveals high cryptic genetic variation and cryptic dispersal potential. Evolution 56:1954-1967.

Stanton B. 1976. Circulation and hydrology off the west coast of the South Island, New Zealand. New Zealand Journal of Marine and Freshwater Research 10:445-467.

Stevens MI, and Hogg ID. 2004. Population genetic structure of New Zealand's endemic corophiid amphipods: evidence for allopatric speciation. Biological Journal of the Linnean Society 81:119-133.

Storey JD, and Tibshirani R. 2003. Statistical significance for genomewide studies. Proceedings of the National Academy of Sciences 100:9440-9445.

van de Casteele T, Galbusera P, and Matthysen E. 2001. A comparison of microsatellite-based pairwise relatedness estimators. Molecular Ecology 10:1539-1549. 10.1046/j.1365294X.2001.01288.x

Veale A, and Lavery S. 2012. The population genetic structure of the waratah anemone (Actinia tenebrosa) around New Zealand. New Zealand Journal of Marine and Freshwater Research 46:523-536. 
796 Veale AJ, and Lavery SD. 2011. Phylogeography of the snakeskin chiton Sypharochiton

797 pelliserpentis (Mollusca: Polyplacophora) around New Zealand: are seasonal near-shore

798 upwelling events a dynamic barrier to gene flow? Biological Journal of the Linnean

$799 \quad$ Society 104:552-563.

800 Wang J. 2011. COANCESTRY: a program for simulating, estimating and analysing relatedness $801 \quad$ and inbreeding coefficients. Molecular Ecology Resources 11:141-145.

802 Wares JP, Gaines SD, and Cunningham CW. 2001. A comparative study of asymmetric 803 migration events across a marine biogeographic boundary. Evolution 55:295-306.

804 Waters J, and Roy M. 2004. Phylogeography of a high-dispersal New Zealand sea-star: does 805 upwelling block gene-flow? Molecular Ecology 13:2797-2806.

806 Weersing K, and Toonen RJ. 2009. Population genetics, larval dispersal, and connectivity in 807 marine systems. Marine Ecology Progress Series 393:1-12.

808 Weir BS, and Cockerham CC. 1984. Estimating F-statistics for the analysis of population $809 \quad$ structure. Evolution:1358-1370.

810 Wellenreuther M, Svensson EI, and Hansson B. 2014. Sexual selection and genetic colour 811 polymorphisms in animals. Molecular Ecology 23:5398-5414.

812 White C, Selkoe KA, Watson J, Siegel DA, Zacherl DC, and Toonen RJ. 2010. Ocean currents 813 help explain population genetic structure. Proceedings of the Royal Society of London B:

815 Xavier R, Zenboudji S, Lima FP, Harris JD, Santos AM, and Branco M. 2011. Phylogeography 816 of the marine isopod Stenosoma nadejda (Rezig, 1989) in North African Atlantic and western Mediterranean coasts reveals complex differentiation patterns and a new species. Biological Journal of the Linnean Society 104:419-431. 
819 Zheng X, Levine D, Shen J, Gogarten SM, Laurie C, and Weir BS. 2012. A high-performance 820 computing toolset for relatedness and principal component analysis of SNP data.

821 Bioinformatics 28:3326-3328.

822

823

824 


\section{Figure 1}

Colour polymorphism in $I$. armatus.

Within an almost continuous range of variation, certain colour morphs can be identified e.g.

(a) and (b) variegated, (c) green, (d) white, (e) no pattern, ( $f$ ) and (g) striped, and (h) spotted. Mature males (c), (e), and (h) possess a dorsal spine on the seventh pereonite. Photos by $\mathrm{S} J$ Wells

a

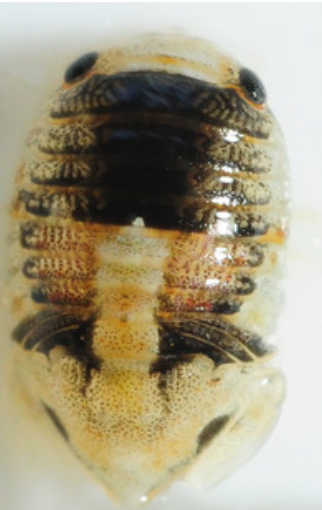

e

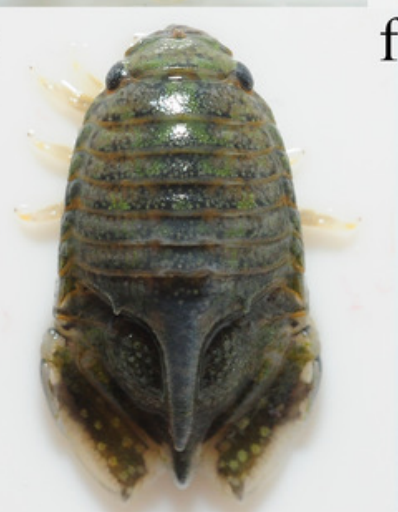

b

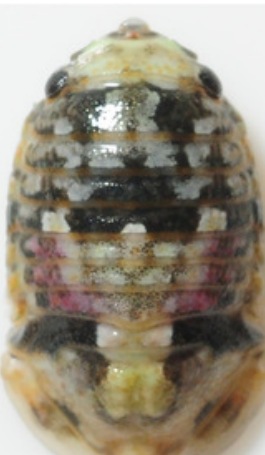

$\mathrm{f}$

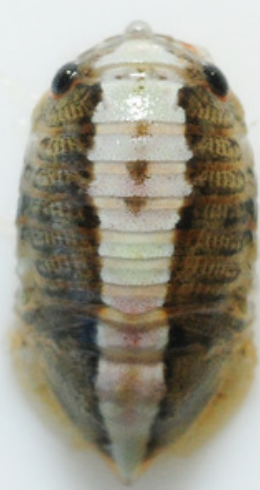

c

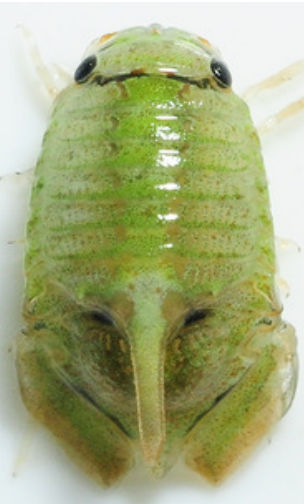

$\mathrm{g}$

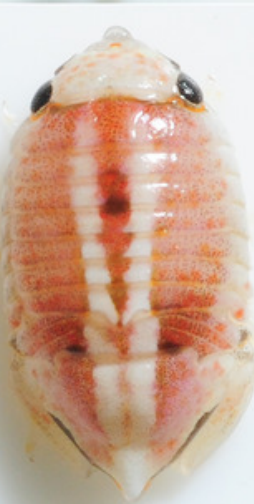

d

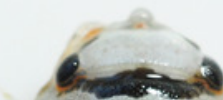

$\mathrm{h}$

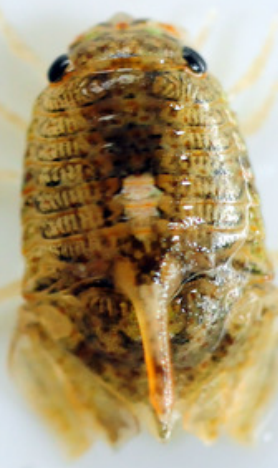


Figure 2

Map showing sampling locations and the major ocean current systems around the New Zealand coast. Adapted from Heath (1985).

WAC: West Auckland Current, EAC: East Auckland Current, ECE: East Cape Eddy, ECC: East Cape Current, WE: Wairarapa Eddy, SC: Southland Current, TC: Tasman Current, WC: Westland Current, DC: Durville Current. 


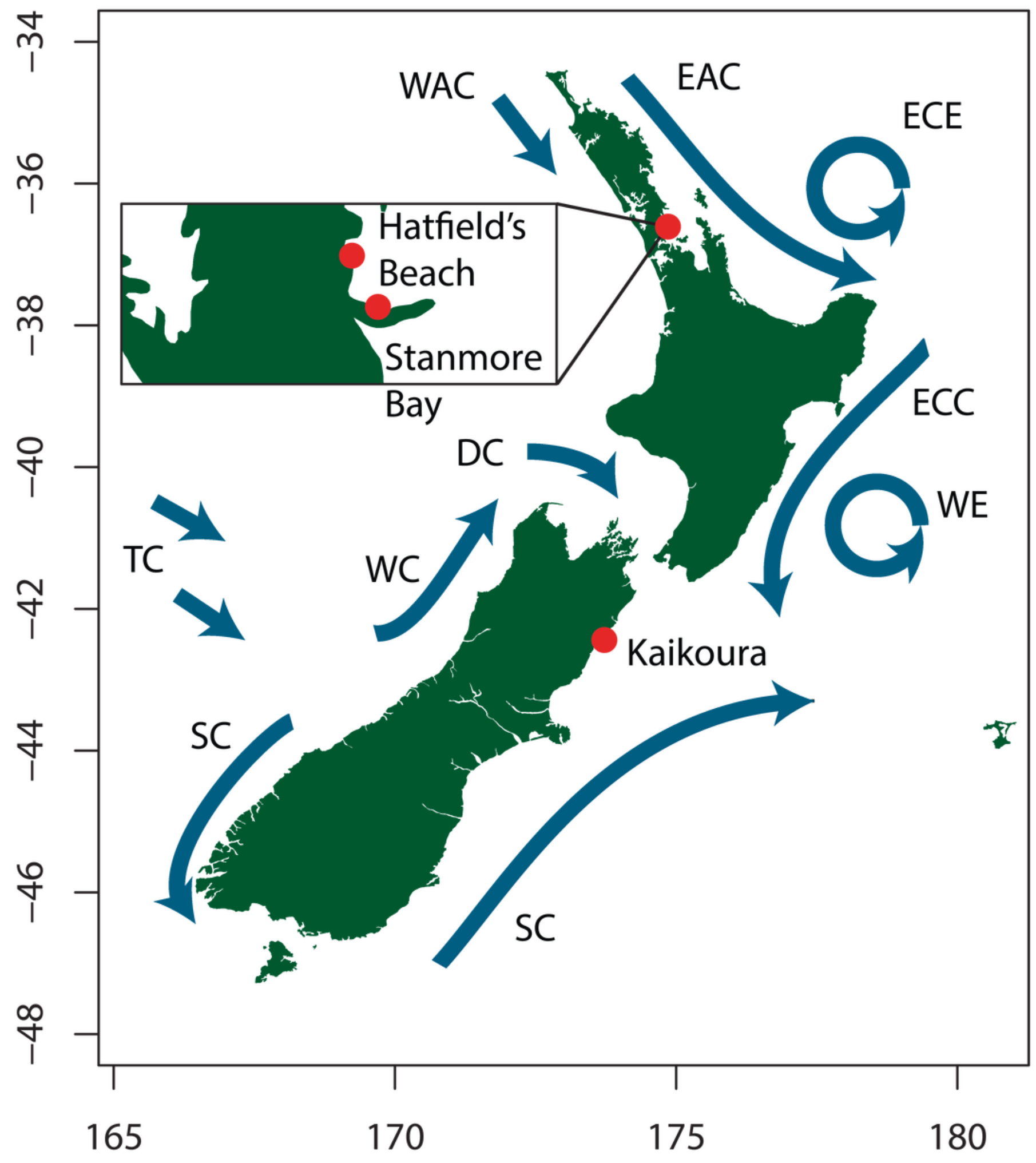


Figure 3

Population genetic diversity statistics.

Tukey's boxplots showing (a) mean observed heterozygosity and (b) the inbreeding coefficient for each population.

(a)

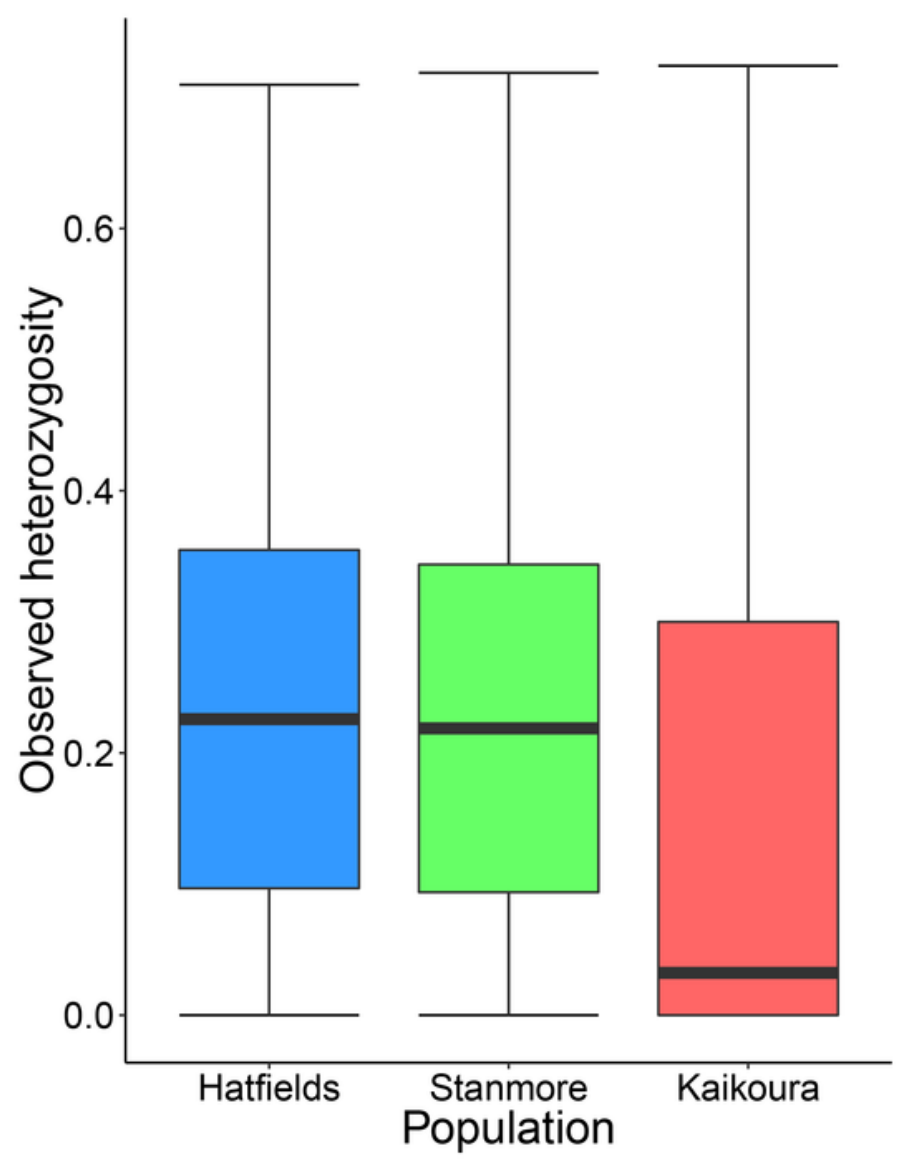

(b)

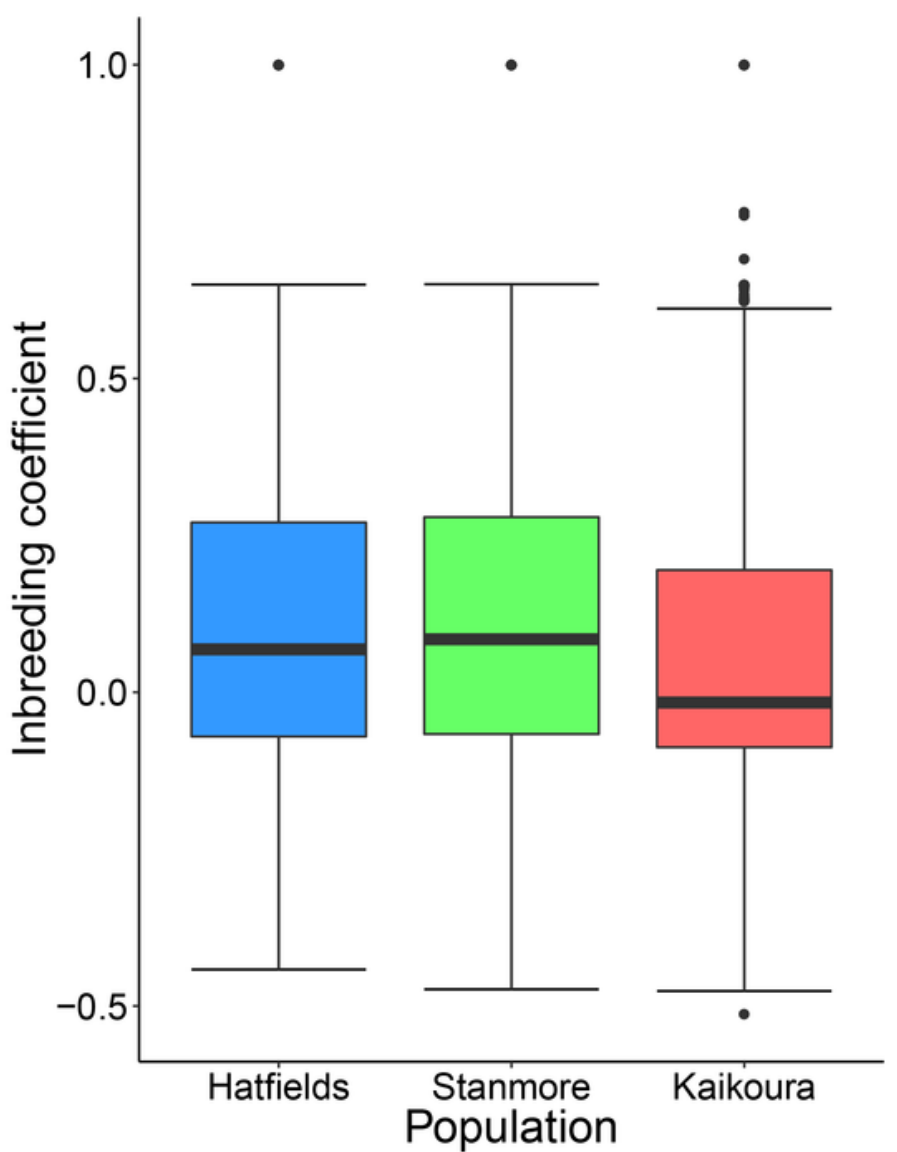


Figure 4

Principal coordinates analysis (PCA) showing individuals coloured by population.

a) PCA with all populations showing distinct clustering of the Kaikoura population with the first and second principal coordinates explaining $27.8 \%$ and $1.2 \%$ of the variance respectively. b) PCA for the North Island populations only with the first and second principal coordinates explaining $2.1 \%$ and $2.1 \%$ of the variance respectively.

(a)

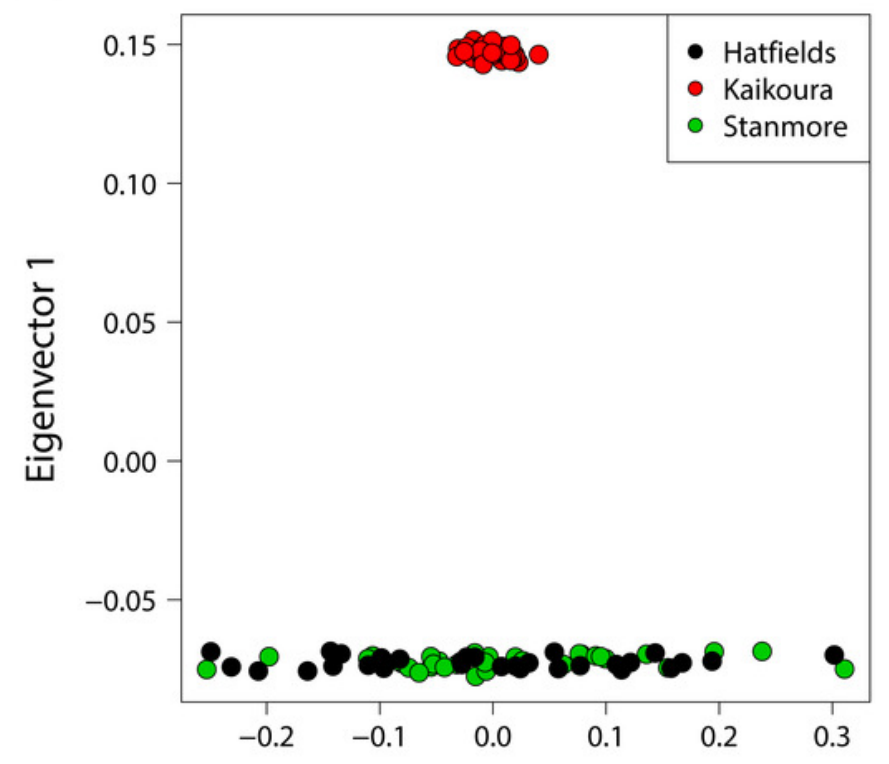

Eigenvector 2 (b)

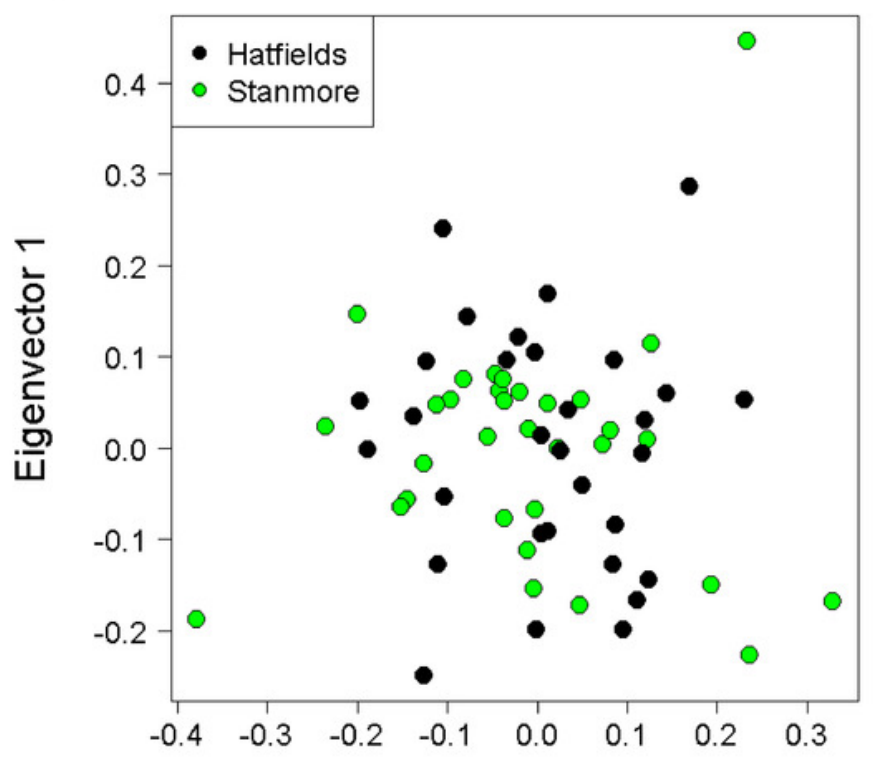

Eigenvector 2 


\section{Figure 5}

Barplots of STRUCTURE results based on Bayesian clustering algorithms.

Barplots have been summarised over 10 replicates and show proportional membership of (a) 94 individuals of $I$. armatus to $K=2$ genetic clusters and b) 32 individuals from Stanmore Bay and 31 individuals from Hatfield's Beach to $K=2$ genetic clusters. Colours indicate proportional membership to a genetic cluster. Individuals are ordered by population of origin with vertical bars representing a single individual. NI: North Island, SI: South Island. 
(a)

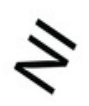

s

s)

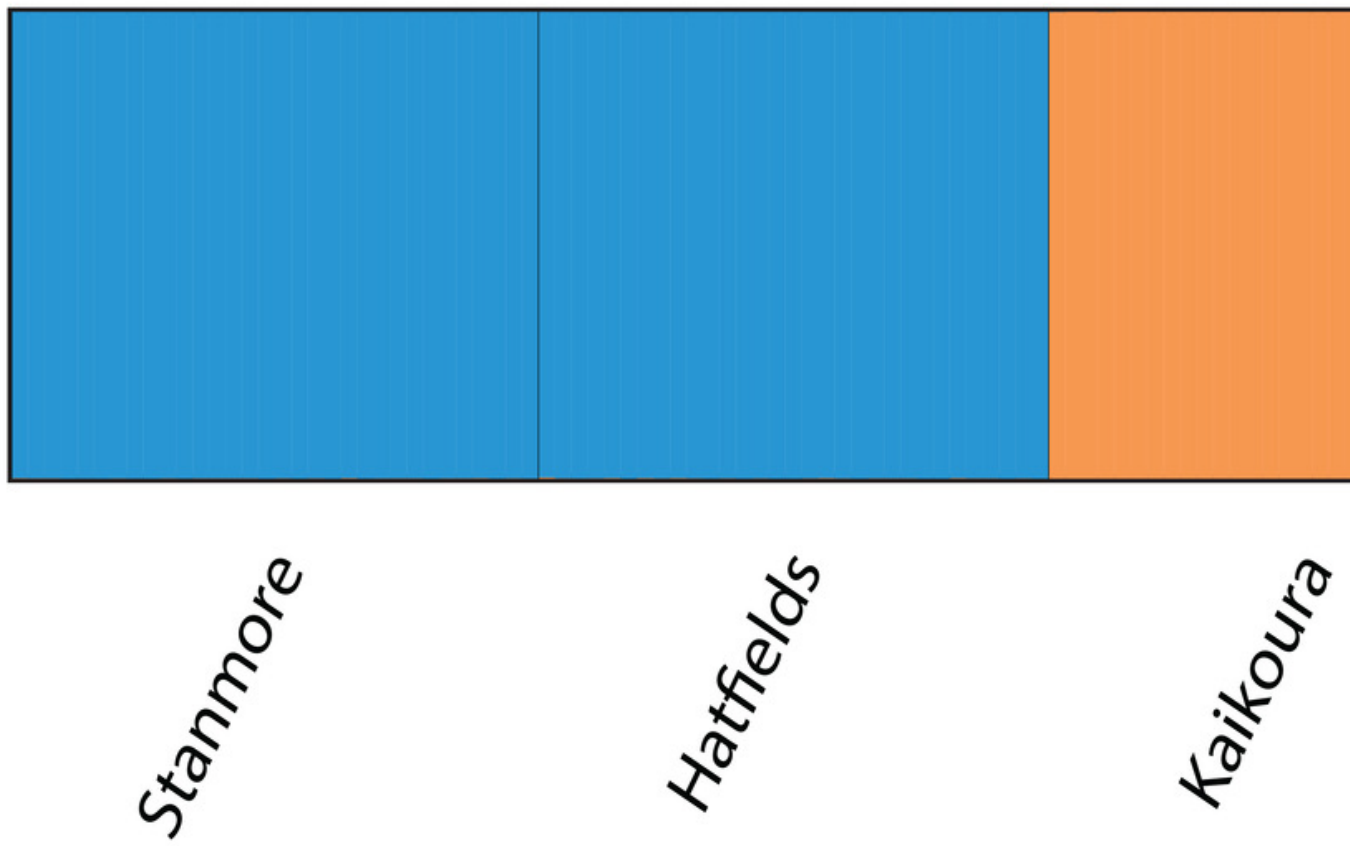

(b)
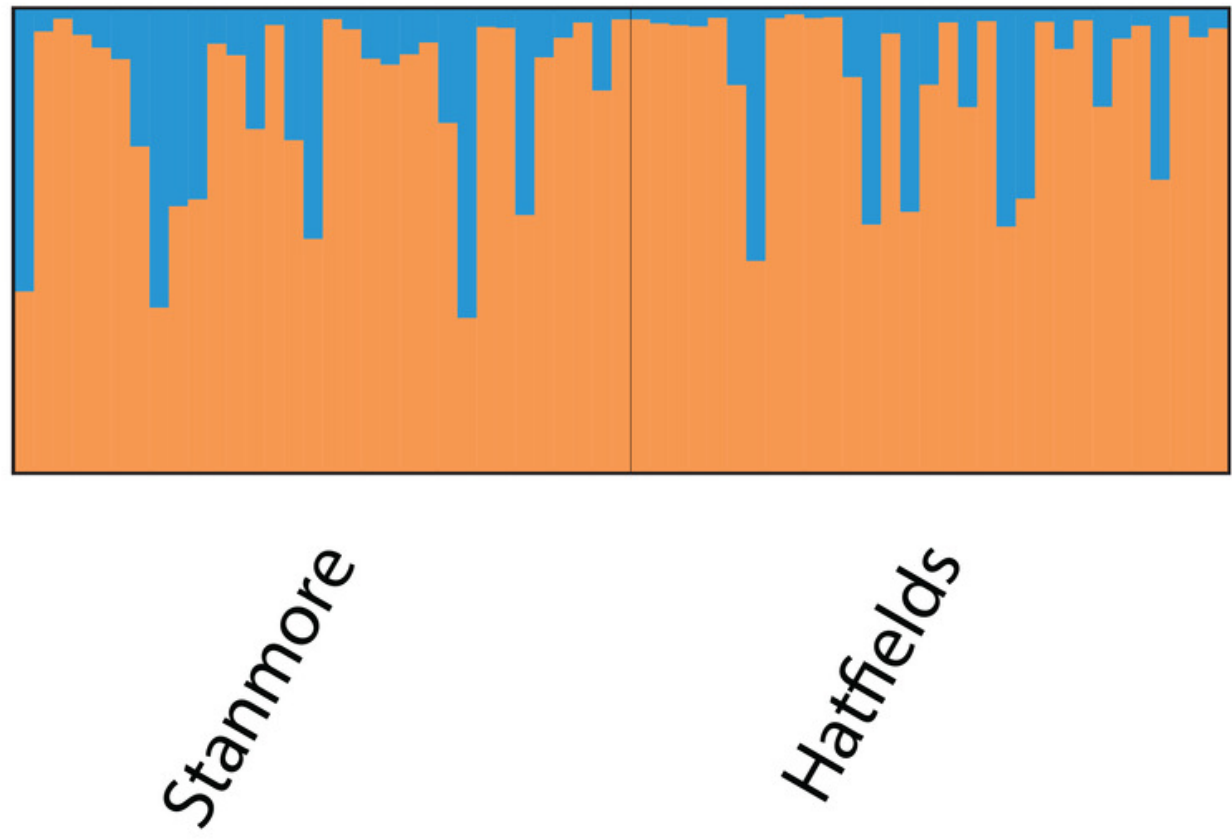
Figure 6

PCA of genetic distance using the six loci deemed under positive selection for colour with individuals coloured by morphotype.

Analysis is for the North Island (Hatfield's Beach and Stanmore Bay) individuals only. Plot shows the first two principal components (PCs). PC1 explained $41.1 \%$ of the variance, while PC2 explained $23.9 \%$ of the variance. Points have been jittered (factor $=100$ ) to improve readability.

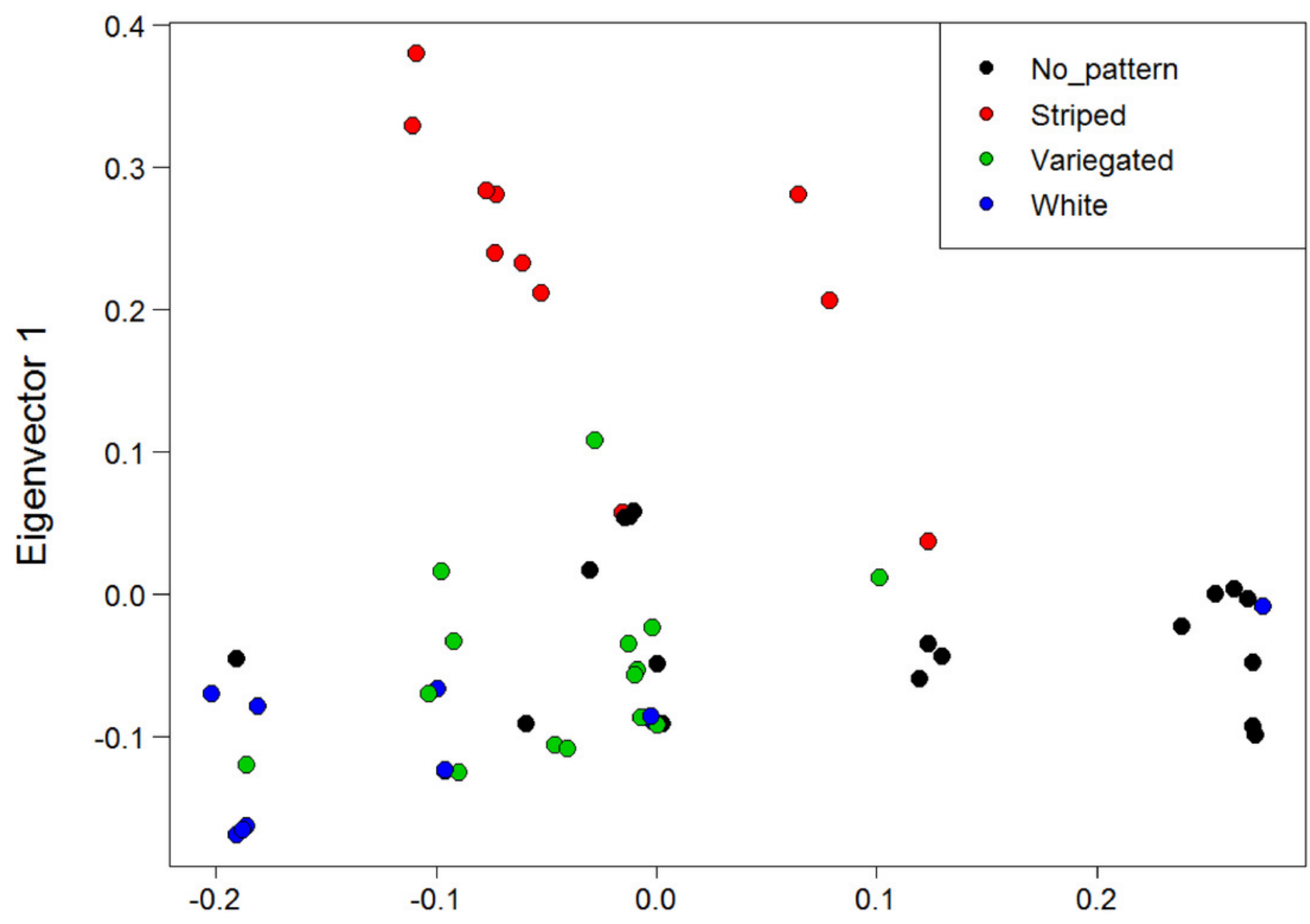

Eigenvector 2 


\section{Table $\mathbf{1}$ (on next page)}

Sample sizes of $I$. armatus populations and numbers of each colour morph sampled at each location 


\begin{tabular}{lcccccc}
\hline & No pattern & White & Variegated & Striped & Unassigned & Total \\
\hline Hatfield's Beach & 10 & 5 & 7 & 3 & 6 & 31 \\
Stanmore Bay & 8 & 7 & 8 & 8 & 1 & 32 \\
Kaikoura & 12 & 3 & 8 & 3 & 5 & 31 \\
\hline
\end{tabular}

1 


\section{Table 2 (on next page)}

Genetic diversity estimates showing the mean value with standard deviation (SD) for each population. 
1

\begin{tabular}{|c|c|c|c|c|}
\hline & $\mathrm{H}_{\mathrm{o}}$ & $\mathrm{H}_{\mathrm{e}}$ & $\mathrm{F}_{\text {IS }}$ & $\mathrm{r}$ \\
\hline Stanmore Bay & 0.223 SD 0.158 & 0.253 SD 0.163 & 0.118 SD 0.236 & $0.018 \mathrm{SD} 0.01$ \\
\hline Hatfield's Beach & 0.229 SD 0.159 & 0.257 SD 0.162 & 0.107 SD 0.235 & 0.016 SD 0.01 \\
\hline Kaikoura & 0.153 SD 0.187 & 0.163 SD 0.190 & 0.059 SD 0.237 & 0.011 SD 0.02 \\
\hline
\end{tabular}

$2 \mathrm{H}_{\mathrm{o}}=$ observed heterozygosity, $\mathrm{H}_{\mathrm{e}}=$ expected heterozygosity, $\mathrm{F}_{\mathrm{IS}}$ : inbreeding coefficient; $\mathrm{r}$ :

3 TrioML pairwise genetic relatedness.

4 